\title{
Earthquake protection for high-speed rail traffic: risky business?
}

\author{
S. Vecchiato ${ }^{1}$, E. Rascol ${ }^{2} \&$ W.-J. Zwanenburg ${ }^{2}$ \\ ${ }^{1}$ INEXIA, France \\ ${ }^{2}$ École Polytechnique Fédérale de Lausanne, Faculté ENAC, Switzerland
}

\begin{abstract}
For earthquake protection of structures (such as bridges, viaducts and embankments), a precise and safe dimensioning has to be calculated according to the soil profile, the location of potentially active faults, and the local liquefaction risk, as they all influence the damaging potential of seismic waves. In many European countries, these measures are considered to be sufficient for structures to withstand earthquakes and to guarantee a proper level of safety (i.e. avoiding a collapse of the structures). High-speed rail lines, however, have very strict limits regarding the position of the track to continue a safe support and guiding of trains running at speeds of $300 \mathrm{~km} / \mathrm{h}$ or more. Even if structures have not collapsed, or landslides have not occurred, the track position after an earthquake can be beyond the limits for safe running at $300 \mathrm{~km} / \mathrm{h}$. This study shows that different countries deal with these strict limits in different ways.
\end{abstract}

Keywords: earthquakes, high-speed trains, embankment, structure dimensioning, monitoring, risk analysis.

\section{Introduction}

High-speed trains running at speeds of at least $300 \mathrm{~km} / \mathrm{h}$ require an excellent geometrical state of the track. All 'unevenness' in excess of certain limits can lead to a derailment of the train. To deal with this, countries with high-speed rail lines, which are subject to earthquakes, have adopted various philosophies. A study was carried out to retrieve these philosophies and their reasons. To fully understand the phenomena, the potential effects of earthquakes on high-speed lines have been briefly investigated. 
This article describes:

- the potential effects of earthquakes on high-speed rail infrastructure;

- the ways to measure the potential earthquake damage;

- some considerations made by several countries in the assessment of the risks associated with seismic effects on high-speed rail;

- the systems which were implemented as a result of these risk assessments.

Special attention is given to France, where an additional system for infrastructure seismic detection has been set up on the LGV Méditerranée between Marseille and Valence.

\section{Potential effects of earthquakes on high-speed rail lines}

\subsection{Profile and characteristics for a typical rail embankment}

In the open countryside, tracks are positioned either in an excavation, on the flat ground, or on an embankment.
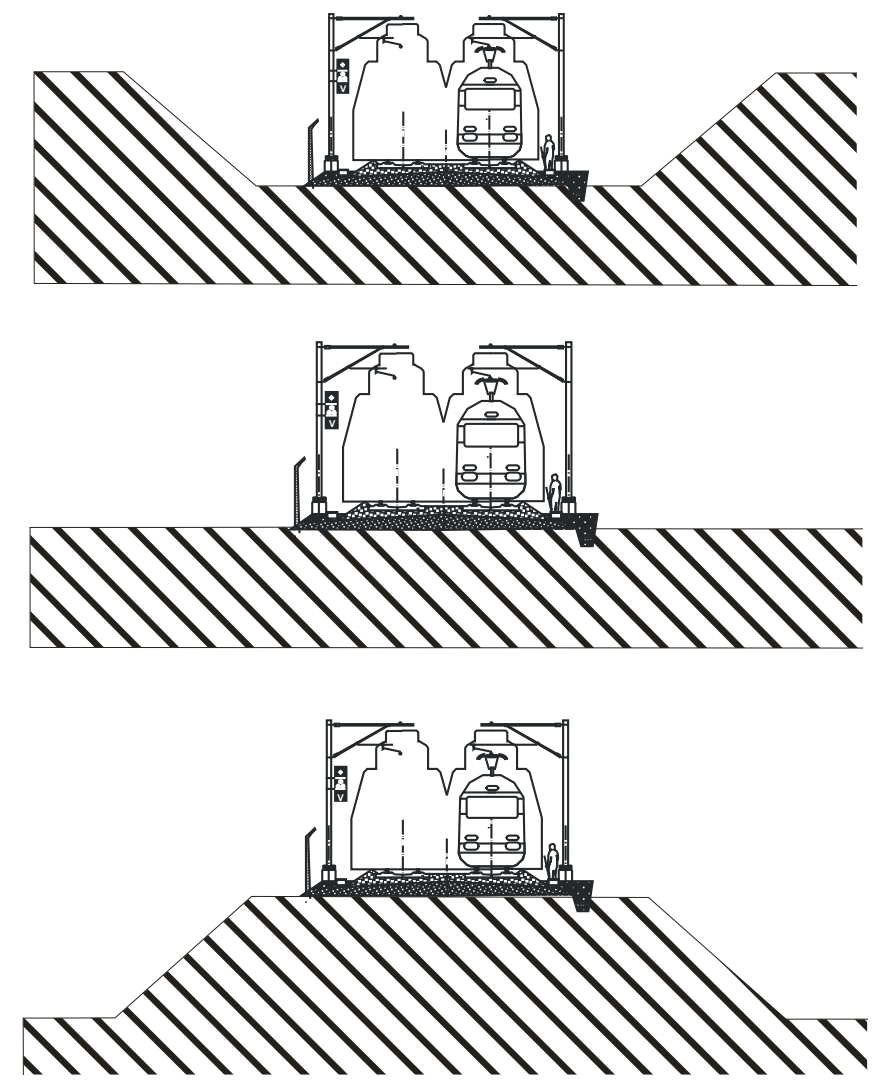

Figure 1: Railway line in an excavation, on flat ground or on an embankment. 
For earthquake safety, the most dangerous situation is the embankment, more precisely, the stability of its slopes is crucial.

The track structure [1] is composed, from top to bottom, of the rails, the sleepers, the ballast bed, possibly some protective layers or improved structures such as geotextiles, and finally, the subsoil. The height of the structure can vary significantly, depending on the soil profile and topography. The dimensions of the track, through the determination of its bearing capacity, depend on the elastic modulus of these components and varies mainly because of subsoil inhomogeneities. In Japan, a country with a large high-speed train network but also frequently confronted with earthquakes, reinforced embankments are now preferred. They have lower encroachment and they have shown improved resistance to strong earthquakes [5].

\subsection{Current earthquake design rules}

The overall stability of railway embankment slopes is assessed by means of ground response analysis. The sliding block model, a widely used technique developed by Newark [3], is a convenient tool used for analyzing slope stability. The static safety factors are taken at 1 1 $\frac{1}{2}$. Starting in 2006, for French high-speed tracks designed for commercial speeds up to $320 \mathrm{~km} / \mathrm{h}$, a special verification has to be carried out in seismic areas. The transversal acceleration, which depends on the soil type, must result in safety factors of one for all embankments. The input loadings are given by design response spectra - in France this is issued by AFPS (Association Française du Génie Parasismique). This simplified criterion prescribes the shape and the intensity of the acceleration, speed, and displacement of different types of soils in the free-field. The site conditions, as well as the damping of the earth structure, are, as far as possible, taken into account inside the acceleration value by means of amplification factors. In case of liquefiable soils, a specific analysis is performed - the minimum safety factor is also one in this case. This results in a conservative design with specific constructive actions, such as soil compaction and reinforcement. Moreover, drainage systems are designed to allow rapid evacuation of any water, limiting the pore pressure, which might cause major loss of strength and a decrease of the bearing capacity.

The geotechnical survey made previous to the track design is assumed to provide a good knowledge of the sensitivity of the site to seismic hazard. The assessment of hazard level is a combination of soil and topography vulnerability with an assessment of the region's seismicity. Soil is classified into groups, depending on its mechanical strength. The classification is different from one country to the other. Depending on the soil category, the amplitude and shape of the design spectra is fixed by local design codes. Indeed, the soil response to an earthquake greatly differs between different geological areas. The characteristics of local seismicity, like earthquake magnitude and frequency content, also highly influence response spectra. 


\subsection{Wave propagation in the embankment profile}

Seismic waves in the soil body are made of compressive wave (or P-waves) and shear waves of two kinds (SH-waves and SV-waves). While the compressive waves are not considered as dangerous and are not taken into account, shear waves can create major deformations and instability of soil structures. The stress waves are irregular in amplitude and frequency, and the decomposition of the recorded signals are known to present frequencies from 0.1 to $10 \mathrm{~Hz}$. Close to the surface, Rayleigh waves might appear as a cause of major damage. They are therefore also important when regarding the stability of railway embankment in the case of an earthquake.

Site effect is an immensely important subject within geotechnical earthquake engineering field. Depending on the location, distance to the source, type of soil, and geometry of the surface (topography), the seismic wave may be amplified in certain areas. The deformation arising as a consequence of the earthquake can be very different from one place to another (i.e. deep clay deposits, as can be found in Mexico City, are known to amplify the deformations).
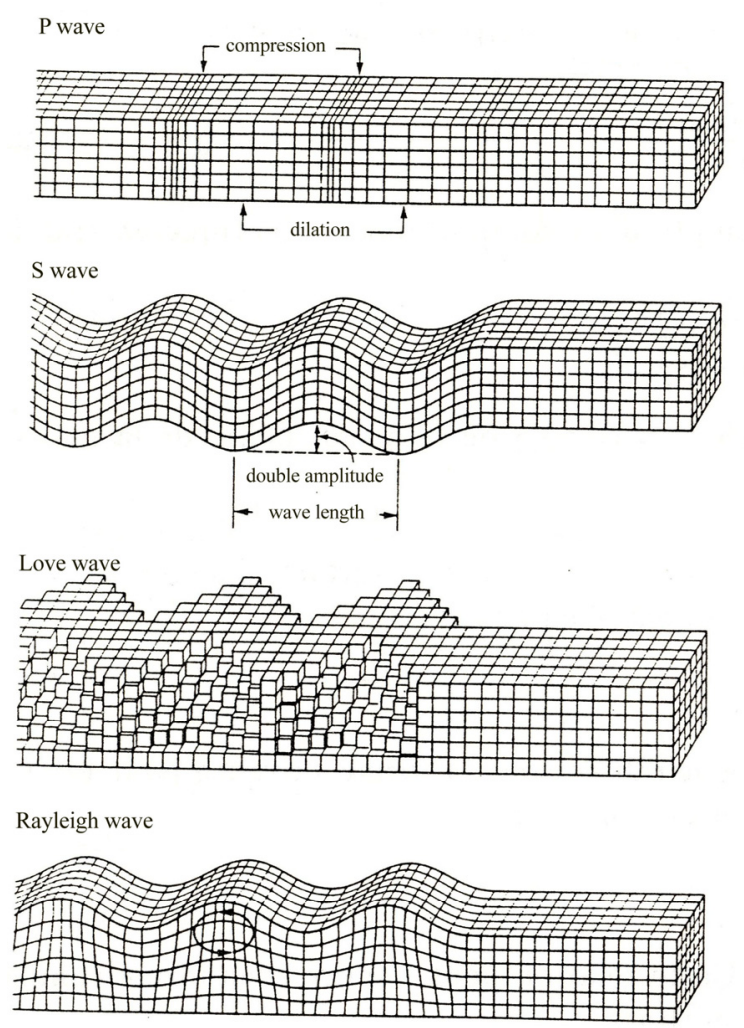

Figure 2: $\quad$ Body waves and surface waves (modified from [4]). 
The natural frequency of rail track embankments is generally assumed circa 1 to $10 \mathrm{~Hz}$. For example, in [2] is presented a $2.4 \mathrm{~Hz}$ natural frequency for a Swedish high-speed railway embankment built on soft soils. The comparison with earthquake frequency range, between $0.1 \mathrm{~Hz}$ and $10 \mathrm{~Hz}$ depending on the earthquake, shows that the propagation of seismic waves inside or around a track embankment might induce resonance of the embankment, thus amplifying the displacements in the structure.

Any model describing the response of the embankment to earthquake loadings is very sensitive to the values of the elastic modulus. The good quality of the measure of this parameter for all the layers of the system is crucial. For sensitive areas, seismic methods - such as seismic reflection and refraction - are efficient tools to measure in-situ the soil properties. An artificial impact induces wave propagation in the track, and receivers record the accelerations of the soil. The travel time of the different kind of waves gives the velocity, which in turn depends on elastic modulus.

\subsection{Consequences on the serviceability of the tracks}

In terms of seismic risks, the main problem is the damage, or even the destruction, of earth structures of regular lines and high-speed lines. The derailment of trains due to excessive deformation of the tracks is the worst case scenario. Site effects in the tracks and induced effects, such as liquefaction or slope failure, can be responsible for such catastrophic events, in case of unfavourable topography. The design of rail embankment takes into account such phenomena. However, in case of extreme events for the region, or in case of hidden weakness of the underground, soil failure can occur. That should be taken into account inside the emergency procedures of railway management companies.

\section{Possibilities to measure the immediate effects of an earthquake for rail safety purposes}

\subsection{Effects of an earthquake under a rolling train}

Beside the effect of an earthquake on the superstructure, the effects as described in $\$ 2.4$ might even be more severe in the case that they occur directly under a rolling train. As shown above, the main effect of earthquakes on railway infrastructures is the wave propagation through all soil and material layers, and then -in case the train is actually rolling in the area hit by the earthquake- their transmission to the rolling stock by the railway superstructure (ballast layer, sleepers, and rails). Those vibrations can induce a dynamic unload of the railwheel contact, resulting in a loss of guidance and thus derailment.

The only means to evaluate the potential effect of an earthquake is to measure the vibration of the ground submitted to seismic waves. Even if intensity and magnitude are the most commonly used parameters to express an earthquake's severity, they cannot be directly measured, but only calculated on the basis of 
acceleration amplitudes and frequencies. These calculations need at least three to five minutes to be processed, which leads to the conclusion that the directly measured ground accelerations (in three directions) are the easiest parameter to immediately evaluate the effect of an earthquake on the infrastructure of a highspeed line.

\subsection{Ground acceleration measurement}

The best location for ground acceleration measurements, with tri-axial sensors for instance, would be the superstructure, or, more exactly rails or sleepers. Indeed, it permits to retrieve the exact vibration transmitted to the rolling stock at the level of the rail-wheel contact surface. Taking into account that these measurements must be used to directly apply safety procedures (i.e. an immediate emergency break procedure of all trains in the vicinity) in case of seismic events only, one major constraint is to guarantee that there is no interference with other important vibration-emitting phenomena. Yet, high-speed train circulation induces a lot of vibrations in rails and sleepers. If the sensors were placed on the superstructure itself, these vibrations could trigger an alarm because of motions unrelated to seismic activity. The conclusion is the same if the sensors are located on the rolling stock and even on the infrastructure, like embankments or excavations.

This implies that any railway earthquake protection system based on ground surface acceleration measurements should use sensors located far enough from the infrastructure. More precisely, places where the probability of seismicunrelated measures is low (i.e. away from truck-circulated roads, huge work areas, industrial plants, etc.), which are still close enough to measure the accelerations at the rail line itself, are best suited. A study lead in France for the Mediterranean high-speed railway showed that a minimum distance of $100 \mathrm{~m}$ from the railway is necessary to sufficiently reduce the effect of train-circulating vibrations.

\section{Railway safety "philosophy" with respect to earthquakes}

Contrary to some phenomena, like crosswinds or water-floods - which are ever better predicted by meteorological or climatic surveillance - earthquakes remain sudden events. They are almost undetectable before they occur, even if many studies are carried out around the world (especially in Japan and California) to improve their predictability. Considering this, two philosophies of protection have been defined, depending on the probability of occurrence of huge seismic events and the local knowledge of seismic activity.

In countries often exposed to damaging earthquakes, like Japan or Taiwan, national seismic protection agencies installed dense networks for seismic surveillance. They are composed of ground acceleration sensors and highperformance calculators set up all over the territory. When an earthquake occurs, the network permits to determine quickly (within a few minutes) the potentially damaged area and to calculate its main parameters: intensity, magnitude, and then ground acceleration on surface over a certain radius. High-speed rail 
earthquake protection systems are based on this network, with additional sensors deployed along the infrastructure. The UrEDAS system (Urgent Earthquake Detection and Alarm System), used for the Shinkansen high-speed rail lines in Japan, is then able, when a seismic P-wave (which is not very destructive, but whose speed propagation is rather high) is detected, to determine within three seconds the maximum radius of the potentially damaged area and then to order an electric power cut in overhead catenaries of railways located in this perimeter. This results immediately in an emergency braking of all trains circulating on those railways. Most of the time, the seismic S-wave (whose speed propagation is slower than the P-wave, but with a much higher destructive potential) reaches the area once the trains are stopped or at least drastically slowed down, which can significantly reduce damage. Nevertheless, when the epicentre is located just below or near the track, damages or derailments are inevitable because S-waves reach the railway line before appropriate countermeasures (i.e. emergency braking) can be applied.

In European countries, damaging seismic events seldom occur and seismicrelated knowledge of terrain is less thorough. Each country has an environmental surveillance or protection agency for environmental risks, but associated networks deployed on territories are less developed and their performance level is lower than in Eastern Asia or California. At the same time, they are considered to be satisfactory for European seismic protection needs. As for railway protection, this implies that different solutions, as compared to the Japanese one, have to be implemented to further reduce the risk of earthquake-induced damages. Indeed, the density of sensor networks and the number and performance of associated calculators do not permit the detection of $\mathrm{P}$-waves and order emergency braking of all trains before more damaging S-waves reach the area of a high-speed line. In other terms, safety philosophy and measures cannot be based on immediate counteraction. Nevertheless, other actions can be implemented against collateral damage, such as reducing or stopping train circulations on a potentially damaged area.

Regarding this point, we observed that several European countries deal with this problem in different ways. Countermeasures are often linked to their global philosophy towards risk analyses and RAMS (Reliability, Availability, Maintainability, Safety) requirements. This point will be discussed below.

\subsection{The particular case in France}

Risk analyses and security-related studies in France are actually based on a principle known as "GAME" , specifying that any new railway system must offer a security level which is "at least globally equivalent" to already existing (i.e. operating in commercial service) railways of the same kind, and especially to the latest commissioned one, considered as the reference. This indirectly implies that any new system to be implemented on a new railway must comply with RAMS specifications of the reference system, which is usually proved through a specific risk analysis (the European norm EN 50126 gives a global methodology for such analyses). This new implementation will also serve as a 
kind of jurisprudence for further projects. Earthquake protection systems are no exception to this.

Since the commissioning of the Valence-Marseilles high-speed rail line (LGV Méditerranée) in 2001, security demands on high-speed rail traffic have considerably increased in France, especially with commercial operations at a 320 $\mathrm{km} / \mathrm{h}$ speed on the latest high-speed lines. Mainly due to the fact that a section of the LGV Méditerranée line had to be built on top of potentially active geological faults, including the Lambesc fault which corresponds to the most important seismic event ever recorded by seismographs on the French metropolitan territory, an additional system for infrastructure seismic protection has been set up on the LGV Méditerranée. Based on ground acceleration measured at 100m from the line, it aims at reducing the risk on collateral damages due to circulations on potentially deformed or destroyed tracks. In case of a dangerous event, this system orders slowdowns or even traffic stops using the electronic track signalling system. Seismic event confirmation or invalidation has to be sent by CEA (Commissariat à l'Energie Atomique) environmental protection centre to the railway OCC (operating control centre). In the case of a false alarm (i.e. the earthquake is not confirmed), circulations can return to normal; if not, restrictions are maintained and railway staff has to go on site to check the infrastructure condition.

In application of the GAME principle, a study lead by Réseau Ferré de France (RFF, French infrastructure management company) [6] was carried out for the Rhine-Rhône high-speed line (between Dijon and Mulhouse, commissioning expected in 2011) to determine which seismic protection system is required. The study first confirms the impossibility to reach the existing LGV Méditerranée security level using only an existing and non-specific earthquake surveillance network. Moreover, the changing of regulations and zonings for earthquakeresistant constructions with the introduction of European regulations "Eurocode 8 " implies that measures taken on this project will be considered as a new reference (or jurisprudence) for the following French projects. This inevitably implies the need to re-evaluate clearly the new issue of infrastructure seismic protection in France, but taking now into account the way it could be defined on a European scale context.

\subsection{Seismic protection in other European countries}

As for other European countries, according to historical archives and seismic measurement over the last decades, seismic risk level in Germany and Switzerland can be considered equivalent to the French situation. In both countries, seismic design of railway structures (bridges and viaducts), embankments and excavations are considered to be sufficient according to national or European engineering norms. This is also true for German high-speed rail lines, on which trains run at 270 to $300 \mathrm{~km} / \mathrm{h}$. In case of a seismic event, the operating control centre is expected to take appropriate actions with regard to train circulations after being alarmed by the national offices for environmental protection. In both Swiss and German approaches, it is considered that a (highspeed) railway-dedicated earthquake warning and counteraction system is not 
necessary. To obtain that conclusion, they contemplated the risks, in terms of probability and consequences, and the incertitude on the locations of the new sensors.

Moreover, the same approach is also used in Italy, especially for new highspeed rail projects in the northern part of the country (Milano-Bologna and Torino-Milano). In this part of Italy, the seismic risk is even higher than in the Rhône-Valley in France, where the LGV Méditerranée is situated.

Thus, seismic protection of railway infrastructure turns out to be a convincing example of remaining divergences among European countries about risk analyses and safety requirements. However, more and more European norms for railway infrastructures and systems design, so-called Technical Specifications for Interoperability or TSI, are being implemented. None of them provide clear RAMS specifications toward environmental risks such as crosswinds, flooding, and earthquakes. As for risk analyses, the European norm EN 50126 only imposes a methodology which is compatible with all different approaches for safety requirements.

\section{Synthesis}

Earthquakes can have serious effects on the state of high-speed rail structures and embankments. Under a seismic event, the tracks can get out of imposed geometrical limits, which can lead to train derailment. Besides the adoption of improved design rules, immediate (automatic) action triggered by earthquake motions is seen as a necessity by some countries. This is the case in Japan, Taiwan, and France.

However, a lack of clear standards for dealing with these risks has resulted in different philosophies, even in the EU, when railways are situated in areas prone to earthquake hazard.

Information on implementation costs and specifications related to reliability (including false-negatives) of automatic systems was unfortunately not publicly available. But the near future will hopefully see TSI implemented for dealing with earthquakes on high-speed railway lines. They should contain an outline of the required systems, depending on regional seismic activity. It would be preferable if they can be implemented in systems based on existing European, standardized technology such as the European Train Control System (ETCS).

An interesting subject in this context is the earthquake protection system which will be implemented on the future California High-Speed Rail, whose commissioning is expected for around 2020.

\section{References}

[1] Lichtberger, B., Track Compendium. Eurailpress, Hamburg, 2005

[2] Madshus, C., and Kaynia, A.M., High-speed railway lines on soft ground: Dynamic behaviour at critical train speed. Journal of Sound and Vibration, 231(3), pp. 689-701, 2000 
[3] Newmark, N.M., Effects of Earthquakes on Dams and Embankments. Geotechnique, 15(2), pp. 139-160, 1965

[4] Semblat, J.F., Sols sous sollicitations dynamiques et transitoire: Réponse dynamique aux barres de Hopkinson, propagation d'ondes en milieu centrifugé, Ecole Polytechnique, Palaiseau, 1994

[5] Tatsuoka, F., Tateyama, M., Mohri, Y., and Matsushima, K., Remedial treatment of soil structures using geosynthetic-reinforcing technology. Geotextiles and Geomembranes, 25(4-5), 204-220, 2007

[6] Vecchiato S., Etude des systèmes de protection sismique et aux vents traversiers sur la LGV Rhin-Rhône Branche Est, Réseau Ferré de France, EPFL Master thesis, 2008. 